\begin{tabular}{|c|c|c|}
\hline \multirow{3}{*}{$\begin{array}{r}\text { Case Reports in } \\
\text { Gastroenterology }\end{array}$} & \multirow{2}{*}{\multicolumn{2}{|c|}{ Case Rep Gastroenterol 2014;8:364-370 }} \\
\hline & & \\
\hline & $\begin{array}{l}\text { DOI: 10.1159/000369549 } \\
\text { Publisned online: November 20, } 2014\end{array}$ & $\begin{array}{l}\text { (c) } 2014 \text { S. Karger AG, Basel } \\
\text { 1662-0631/14/0083-0364\$39.50/0 } \\
\text { www.karger.com/crg }\end{array}$ \\
\hline & \multicolumn{2}{|c|}{$\begin{array}{l}\text { This is an Open Access article licensed under the terms of the Creative Common } \\
\text { Attribution-NonCommercial } 3.0 \text { Unported license (CC BY-NC) (www.karger.com/OA } \\
\text { license), applicable to the online version of the article only. Distribution permitted for non } \\
\text { commercial purposes only. }\end{array}$} \\
\hline
\end{tabular}

\title{
Appendiceal Abscesses Reduced in Size by Drainage of Pus from the Appendiceal Orifice during Colonoscopy: A Report of Three Cases
}

\author{
Shinjiro Kobayashi Ryoji Makizumi Kazunari Nakahara \\ Satoshi Tsukikawa Nobuyoshi Miyajima Takehito Otsubo \\ Division of Gastroenterological and General Surgery, St. Marianna University School of \\ Medicine, Kawasaki, Japan
}

\section{Key Words}

Appendiceal abscess · Appendectomy · Laparoscopic appendectomy · Interval appendectomy $\cdot$ Colonoscopy

\begin{abstract}
Interval appendectomy (IA) for appendiceal abscesses is useful for avoiding extended surgery and preventing postoperative complications. However, IA has problems in that it takes time before an abscess is reduced in size in some cases and in that elective surgery may result in a delay in treatment in patients with a malignant tumor of the appendix. In order to rule out malignancy, we performed colonoscopy on three patients with an appendiceal abscess that did not decrease in size 5 or more days after IA. After malignancy had been ruled out by examination of the area of the appendiceal orifice, the appendiceal orifice was compressed with a colonoscope, and a catheter was inserted through the orifice. Then, drainage of pus was observed from the appendiceal orifice into the cecal lumen. Computed tomography performed 3 days after colonoscopy revealed a marked reduction in abscess size in all patients. No endoscopy-related complication was noted. Colonoscopy in patients with an appendiceal abscess may not only differentiate malignant tumors, but also accelerate reduction in abscess size.

(C) 2014 S. Karger AG, Basel
\end{abstract}


Kobayashi et al.: Appendiceal Abscesses Reduced in Size by Drainage of Pus from the Appendiceal Orifice during Colonoscopy: A Report of Three Cases

\section{Introduction}

Interval appendectomy (IA) for appendiceal abscesses is useful for avoiding extended surgery and reducing postoperative complications [1]. However, IA has problems in that it takes time before an abscess is reduced in size in some cases and in that elective surgery may result in a delay in treatment in patients with a malignant tumor of the appendix [1]. In order to rule out malignancy, we performed colonoscopy on three patients with an appendiceal abscess who chose to undergo IA, but whose abscess did not decrease in size after 5 or more days of treatment with an antibiotic. During the routine procedure of colonoscopy in these patients, drainage of pus was incidentally observed from the area of the appendiceal orifice into the cecal lumen. The abscesses were reduced in size early after colonoscopy. We herein report that performing colonoscopy in patients with an appendiceal abscess may accelerate reduction of abscess size.

\section{Case 1}

A man in his seventies had an appendiceal abscess $50 \mathrm{~mm}$ in diameter (fig. 1a). On admission, he had increased inflammatory markers (white blood cell count $11,500 / \mu \mathrm{l}$, C-reactive protein $4.6 \mathrm{mg} / \mathrm{dl}$ ), but examination of the abdomen revealed only tenderness localized to the right lower quadrant of the abdomen. Since he wanted to undergo IA, he was fasted after admission and administered an antibiotic ( $4 \mathrm{~g} /$ day of flomoxef sodium). Computed tomography (CT) imaging performed 5 days after admission revealed no reduction in size of the abscess, and therefore colonoscopy was performed the following day. Redness and edema of the mucosa were observed in the area of the appendiceal orifice, but no finding suggestive of malignancy was observed. The area of the appendiceal orifice was examined, followed by compression with a colonoscope. Then, a large amount of pus drained from the appendix (fig. 1b). During the examination, the patient's general condition remained normal, and abdominal pain did not develop. After the examination, there was no increase in inflammatory markers and abdominal pain did not worsen; rather, they were improved. CT imaging performed 3 days after colonoscopy revealed that the abscess had almost resolved (fig. 1c).

\section{Case 2}

A man in his fifties had an appendiceal abscess $50 \mathrm{~mm}$ in diameter (fig. 2a). Treatment with IA was decided, and the patient was fasted after admission and administered an antibiotic, as in case 1 . Since the abscess did not decrease in size, colonoscopy was performed 10 days after admission. As a result, no finding suggestive of malignancy was observed in the area of the appendiceal orifice. After examination, this area was compressed with the colonoscope, but only a small amount of pus drained from the appendix. Subsequently, a dye-spraying catheter was inserted through the appendiceal orifice. Then, a large amount of pus was aspirated from the appendix (fig. 2b). Colonoscopy was completed without any complication, and abdominal pain was improved from the following day. CT imaging performed the day after colonoscopy revealed that the size of the abscess had decreased to $20 \mathrm{~mm}$ in diameter (fig. 2c). The patient was discharged 3 days after colonoscopy. 
Kobayashi et al.: Appendiceal Abscesses Reduced in Size by Drainage of Pus from the Appendiceal Orifice during Colonoscopy: A Report of Three Cases

\section{Case 3}

A woman in her forties had an appendiceal abscess $40 \mathrm{~mm}$ in diameter (fig. 3a). On admission, white blood cell count was 9,300/ $\mu \mathrm{l}$ and C-reactive protein was $5.7 \mathrm{mg} / \mathrm{dl}$. Since abdominal CT imaging performed 4 days after admission revealed no reduction in the size of the abscess, colonoscopy was performed the following day. After confirming that there was no finding suggestive of malignancy in the appendix, a dye-spraying catheter was inserted through the appendiceal orifice. Then, a large amount of pus was aspirated from the appendix. Furthermore, a large amount of pus drained from the appendiceal orifice into the cecal lumen (fig. 3b). CT imaging performed the day after colonoscopy revealed that the abscess had decreased to $20 \mathrm{~mm}$ in diameter (fig. 3c).

\section{Discussion}

An appendiceal abscess is a condition in which an abscess is formed around the appendix as a result of appendiceal perforation or extension of inflammation to the adjacent tissues due to aggravation of appendicitis. It occurs in 2-6\% of patients with appendicitis [2]. IA is a therapeutic strategy used to treat appendiceal abscesses, in which the condition is treated conservatively without surgery in the acute phase, and appendectomy is performed after inflammation has subsided. This strategy has conventionally been used aggressively to manage appendicitis in children [3]. In recent years, it has also been employed for appendiceal abscesses in adults to avoid extended surgery or to prevent postoperative complications [4]. Conservative treatment has been reported to be successful in as many as $80-100 \%$ of patients with appendicitis with abscess formation if inflammation was localized [5]. Some patients require percutaneous drainage [6], but most patients can be treated conservatively. However, more than a few patients do not respond to conservative treatment. A longer time to reduction of an abscess means higher medical expenses, and elective surgery may result in a delay in detection of a malignant tumor of the appendix [7]. Therefore, in order to rule out malignancy, we performed colonoscopy on patients whose abscess was not reduced in size after IA. We think that this intervention accelerated the reduction in abscess size and shortened the length of hospital stay required for IA. There have been six reports (including Japanese papers), such as by Said et al. [8] and Ohtaka et al. [9], of cases of appendiceal abscesses that were incidentally drained by endoscopy. In all these cases, endoscopy was performed to search for the cause of abscess formation, as was done in our patients. The abscess drained from the appendiceal orifice during the course of performing biopsy in five of these patients, excluding one. In three of the five patients who underwent surgery after the abscess was drained, appendectomy was the only surgical procedure performed. Performing endoscopy during abscess formation involves a risk of complications, such as perforation, but endoscopy was performed safely in our three patients and the six patients previously reported. It was reported that cecal cancer, diverticulum of the large intestine or Crohn's disease was diagnosed at a later date in some patients who had undergone CTguided percutaneous drainage, and this may result in a delay in diagnosis [10]. On the other hand, cancer or Crohn's disease can possibly be found by endoscopic drainage, because the mucosa of the large intestine or appendix can be directly observed. We anticipate that drainage of an abscess by endoscopy, which allows examination of the large intestine including the area of the appendiceal orifice, will be an option for the treatment of appendiceal abscesses in the future. 


\begin{tabular}{l|l}
\hline \multicolumn{2}{l}{ Case Rep Gastroenterol 2014;8:364-370 } \\
\hline DOI: 10.1159/000369549 & $\begin{array}{l}\text { C 2014 S. Karger AG, Basel } \\
\text { www.karger.com/crg }\end{array}$ \\
\hline
\end{tabular}

Kobayashi et al.: Appendiceal Abscesses Reduced in Size by Drainage of Pus from the Appendiceal Orifice during Colonoscopy: A Report of Three Cases

\section{Disclosure Statement}

The authors declare no conflict of interests for this article.

\section{References}

-1 Andersson RE, Petzold MG: Nonsurgical treatment of appendiceal abscess or phlegmon: a systematic review and meta-analysis. Ann Surg 2007;246:741-748.

-2 Bagi P, Dueholm S: Nonoperative management of the ultrasonically evaluated appendiceal mass. Surgery 1987;101:602-605.

-3 Weber TR, Keller MA, Bower RJ, Spinner G, Vierling K: Is delayed operative treatment worth the trouble with perforated appendicitis is children? Am J Surg 2003;186:685-689.

4 Lai HW, Loong CC, Chiu JH, Chau GY, Wu CW, Lui WY: Interval appendectomy after conservative treatment of an appendiceal mass. World J Surg 2006;30:352-357.

5 Skoubo-Kristensen E, Hvid I: The appendiceal mass: results of conservative management. Ann Surg 1982;196:584-587.

6 Brown CV, Abrishami M, Muller M, Velmahos GC: Appendiceal abscess: immediate operation or percutaneous drainage? Am Surg 2003;69:829-832.

7 Carpenter SG, Chapital AB, Merritt MV, Johnson DJ: Increased risk of neoplasm in appendicitis treated with interval appendectomy: single-institution experience and literature review. Am Surg 2012;78:339-343.

-8 Said M, Ledochowski M, Dietze 0, Simader H: Colonoscopic diagnosis and treatment of acute appendicitis. Eur J Gastroenterol Hepatol 1995;7:569-571.

-9 Ohtaka M, Asakawa A, Kashiwagi A, Fujino MA, Kasai H, Matsumoto Y: Pericecal appendiceal abscess with drainage during colonoscopy. Gastrointest Endosc 1999;49:107-109.

10 Lee WS, Choi ST, Lee JN, Kim KK, Park YH, Baek JH: A retrospective clinicopathological analysis of appendiceal tumors from 3,744 appendectomies: a single-institution study. Int J Colorectal Dis 2011;26: 617-621. 
Kobayashi et al:: Appendiceal Abscesses Reduced in Size by Drainage of Pus from the Appendiceal Orifice during Colonoscopy: A Report of Three Cases

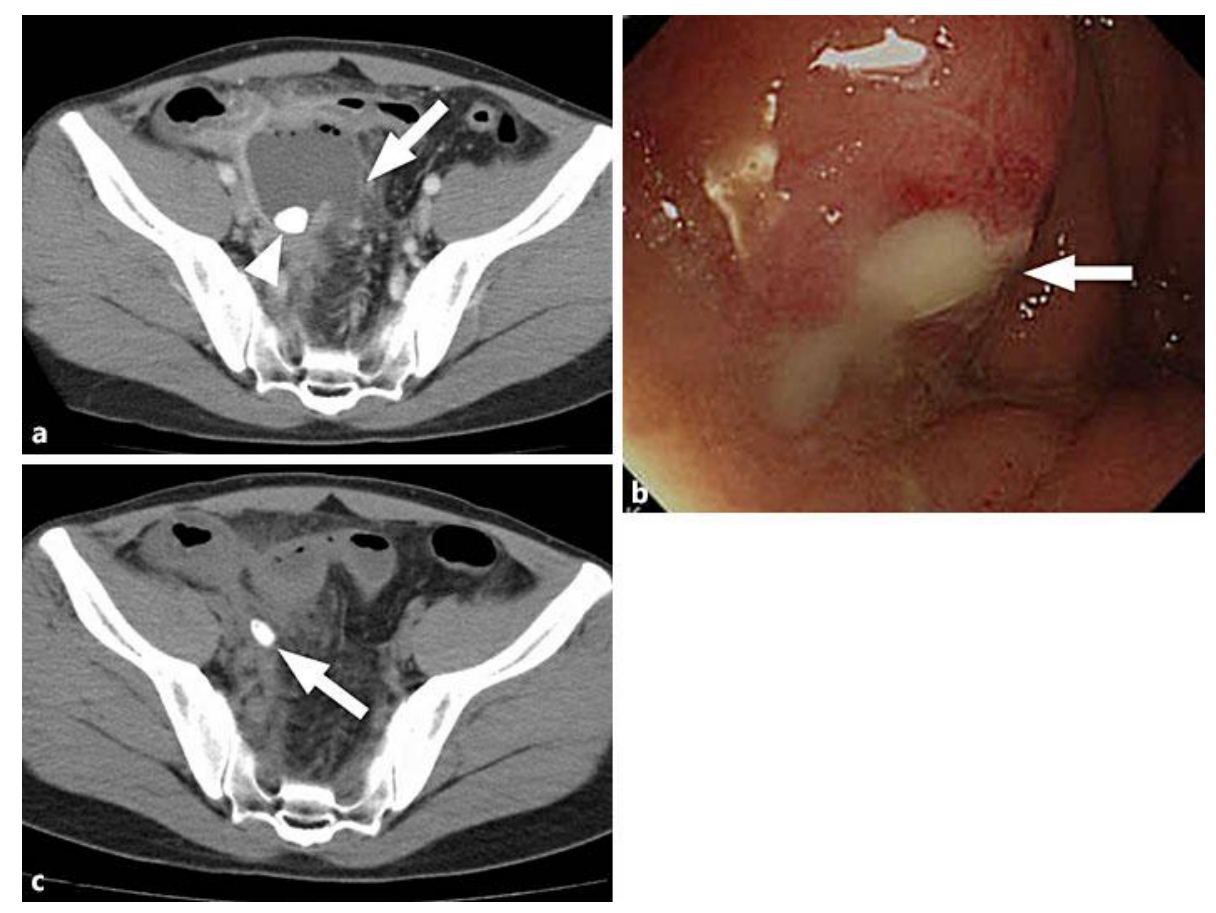

Fig. 1. a An abscess $(53 \times 52 \mathrm{~mm})$ was detected in the pelvis (arrow). A fecalith was also observed in the abscess (arrowhead). b When the area of the appendiceal orifice was compressed with a colonoscope, a large amount of white pus drained from the appendix (arrow). c CT imaging performed 3 days after colonoscopy revealed that the abscess had almost resolved and only the fecalith remained (arrow). 
Kobayashi et al:: Appendiceal Abscesses Reduced in Size by Drainage of Pus from the Appendiceal Orifice during Colonoscopy: A Report of Three Cases

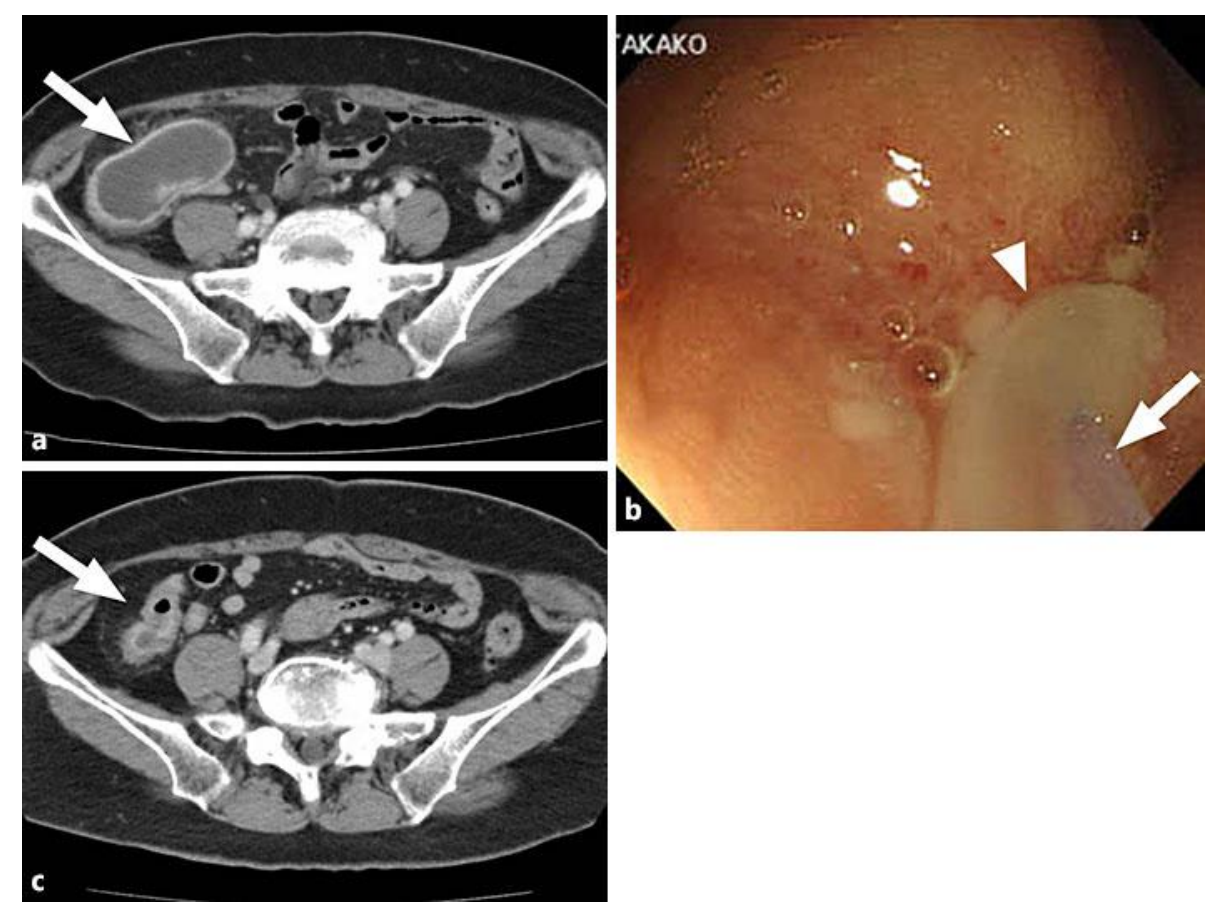

Fig. 2. a An abscess $(55 \times 30 \mathrm{~mm})$ was observed adjacent to the appendix (arrow). b When a dye-spraying catheter was inserted through the appendiceal orifice (arrow), a large amount of white pus was aspirated from the appendix (arrowhead). c CT imaging performed the day after colonoscopy revealed that the abscess had decreased to $20 \mathrm{~mm}$ in diameter (arrow). 
Kobayashi et al:: Appendiceal Abscesses Reduced in Size by Drainage of Pus from the Appendiceal Orifice during Colonoscopy: A Report of Three Cases
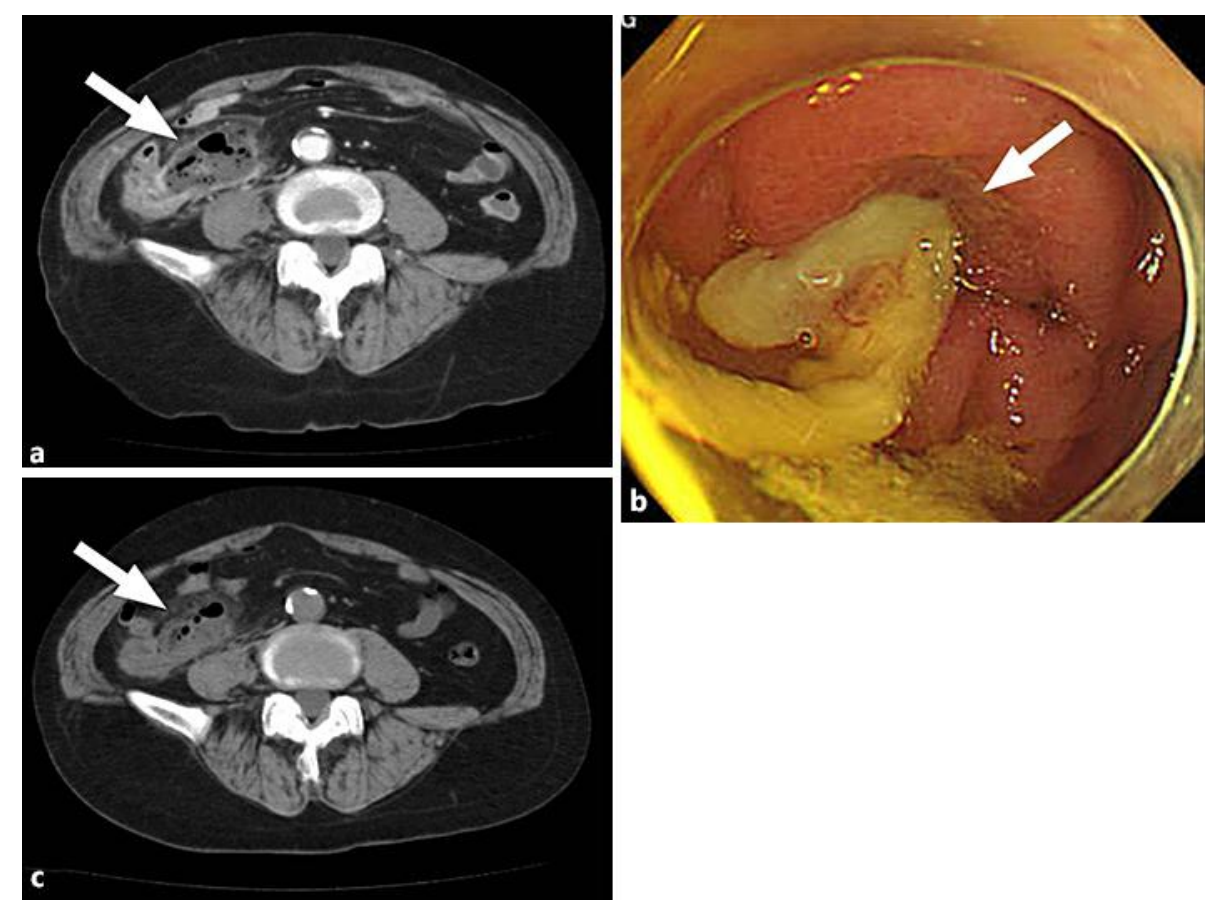

Fig. 3. a An abscess $(40 \times 30 \mathrm{~mm})$ was observed adjacent to the appendix (arrow). $\mathbf{b}$ When a dye-spraying catheter was inserted through the appendiceal orifice, pus was aspirated. When the catheter was removed, a large amount of pus drained from the appendiceal orifice into the cecal lumen (arrow). c CT imaging performed the day after colonoscopy revealed that the abscess had decreased to $20 \mathrm{~mm}$ in $\mathrm{di}$ ameter (arrow). 